\title{
Participar num estudo de aula: A perspetiva dos professores
}

\section{Marisa Quaresma}

Instituto de Educação, Universidade de Lisboa

mq@campus.ul.pt

\section{João Pedro da Ponte}

Instituto de Educação, Universidade de Lisboa

jpponte@ie.ulisboa.pt

\begin{abstract}
Resumo
O estudo de aula é um processo de desenvolvimento profissional originário da cultura japonesa, onde está profundamente enraizado. Muitas adoções noutros países procuram seguir exatamente o que se faz no Japão. Contudo, os processos de ensino-aprendizagem são marcados pelas culturas nacionais e isso tem levado a investigar as adaptações necessárias para a adequação do estudo de aula a diferentes contextos. Assim, o nosso objetivo é saber o modo como participantes em estudos de aula em Portugal percecionam este processo formativo no que respeita à sua dinâmica e à perspetiva curricular. Apresentamos uma conceção geral sobre estudos de aula bem como as adaptações feitas nos estudos que desenvolvemos. Ilustramos com um exemplo realizado com professores do $1 .^{\circ}$ ciclo do ensino básico, referindo o balanço feito pelos participantes. Terminamos com uma discussão sobre as adaptações feitas neste processo formativo, procurando sistematizar a razão de ser das suas potencialidades.
\end{abstract}

Palavras-chave: Estudo de aula. Desenvolvimento profissional. Abordagem exploratória. Formação contínua. Ensino Básico.

\section{To participate in a lesson study: The teachers' perspective}

\begin{abstract}
Lesson study is a process of professional development originating in the Japanese culture where is deeply rooted. Many adoptions in other countries seek to follow exactly what is done in Japan. However, teaching and learning are marked by national cultures and that led to investigate the necessary adaptations of lesson studies to different contexts. So, our goal is to know how teachers who participated in lesson studies in Portugal view this formative process with regard to its dynamic and curricular perspective. We present a general conception about lesson studies as well as the adaptations made in the studies that we developed. We illustrate with an example carried out with primary teachers, referring to the reflection made by the participants. We end with a discussion about the adaptations made to this formative process, seeking to systematize the reasons for its formative potential.
\end{abstract}


Keywords: Lesson Study. Professional Development. Exploratory approach. Teacher Education. Primary teaching.

\section{Introdução}

Originário do Japão, o estudo de aula é hoje praticado por todo o mundo, sendo encarado como um processo de desenvolvimento profissional de professores de caráter colaborativo e reflexivo, centrado na prática letiva (LEWIS, 2002). Trabalhando em conjunto, os professores procuram identificar dificuldades dos alunos, definem objetivos, analisam documentos curriculares e de ensino e preparam uma aula que possa levar os alunos a superarem as dificuldades identificadas e a atingir os objetivos definidos. Observam essa aula, analisam em que medida atinge os objetivos definidos e permite ultrapassar as dificuldades identificadas. Desse modo constitui um processo próximo de uma pequena investigação sobre a própria prática profissional.

Associado aos estudos de aula no Japão, Stiegler e Hiebert (1999) identificaram um certo padrão na estrutura das aulas de Matemática que definiram como structured problem solving. Fujii (2016) refere que esta abordagem é intrínseca à cultura japonesa e tem por base tanto a estrutura da aula como as tarefas apresentadas. De acordo com este autor, as aulas têm, tipicamente, quatro fases: apresentação da tarefa; trabalho autónomo dos alunos; comparação e discussão das resoluções dos alunos; e síntese da aula feita pelo professor. As tarefas são desafiantes e possibilitam o uso de diferentes estratégias. Em Portugal adotamos uma abordagem curricular com alguns pontos em comum com esta abordagem, que denominamos por “abordagem exploratória”, na qual damos especial atenção à natureza das tarefas, à comunicação e ao desenvolvimento do raciocínio dos alunos (PONTE, 2005). Estes são convidados a exercer um papel ativo na interpretação das tarefas propostas, na representação da informação dada e na construção e desenvolvimento de estratégias de resolução que são depois chamados a apresentar e justificar.

Segundo Lewis e Perry (2017), a melhoria do ensino requer um esforço substancial e contínuo por parte dos professores para integrarem inovações na sua prática letiva, mas, para que isso aconteça, é muito importante a sua motivação. Para manter a motivação dos professores é necessário que a introdução desses processos inovadores envolva também o seu conhecimento e que não passe apenas pela imposição de estratégias sem sentido para eles. As mudanças bem-sucedidas requerem o seu envolvimento e a reorganização dos seus conhecimentos e conceções.

Dada a sua natureza prática e reflexiva, os EA podem ajudar os professores a envolver-se em mudanças bem-sucedidas. Tal como tem vindo a ser cada vez mais discutido na investigação internacional (DOIG; GROVES, 2012; STIEGLER; HIBERT, 2016; WAKE; SWAN; FOSTER, 
2016) o grande desafio que se coloca às comunidades fora do Japão interessadas nos estudos de aula é compreender como adaptá-los aos diferentes contextos culturais. Assim, o nosso objetivo é saber o modo como os participantes em estudos de aula por nós desenvolvidos e conduzidos percecionam este processo formativo no que diz respeito à sua dinâmica e à sua perspetiva curricular.

\section{Estudos de Aula}

Fernandez e Yoshida (2004) mencionam que o estudo de aula terá tido a sua origem nos anos de 1890, mas Shimizu (2013) refere que isso pode ter acontecido mais cedo, no início da Idade Moderna (1453-1789). Assim, no Japão, o estudo de aula conta com mais de um século de história, tendo sido sujeito a muitas alterações e adaptações (SHIMIZU, 2013). O termo original japonês é jogoyokenkyu e significa, literalmente, “estudo da aula”.

A divulgação dos estudos de aula no mundo ocidental foi feita através do livro The Teaching Gap (STIEGLER; HIBERT, 1999). Nestes 20 anos desenvolveu-se bastante investigação sobre este processo formativo em numerosos países. Por um lado tenta-se saber como é que se desenvolve, efetivamente, este processo no Japão (TAKAHASHI, 2014). Por outro lado, existem inúmeras tentativas de adaptação a diferentes contextos e culturas, surgindo assim diferentes perspetivas e modelos dos estudos de aula (WAKE; SWAN; FOSTER, 2016). Na sua essência, todos os estudos de aula têm uma estrutura bem definida e coerente, com um núcleo comum de planificação, observação e reflexão. Assim, o grupo começa por definir um problema que gostaria de ver resolvido sobre o ensino e aprendizagem dos seus alunos. Com base nesse problema, desenvolve colaborativamente um plano de aula. Seguidamente, acontece a aula de investigação, onde um dos professores leciona a aula enquanto os restantes colegas observam. Geralmente, são recolhidos dados detalhados do trabalho dos alunos e do professor para discussão posterior. Por fim, segue-se a reflexão pós-aula focando-se em questões como o papel da tarefa implementada, as respostas dos alunos à tarefa e a adequação das questões colocadas pelo professor (FERNADEZ; YOSHIDA, 2004; FUJII, 2016; LEWIS, 2002; MURATA, 2011; SHIMIZU, 2014; STIEGLER; HIEBERT, 1999).

O estudo desenvolvido por Yoshida (FERNANDEZ; YOSHIDA, 2004) numa escola de Hiroxima teve muita influência em trabalhos posteriores, nomeadamente nas propostas de Lewis (2002) e Murata (2011) que sugerem, ainda que com caráter opcional, um processo de reformulação da aula ("re-teaching”). Ou seja, depois da reflexão sobre a aula de investigação, o grupo volta a reunir-se para reformular a aula que, de seguida, é lecionada por outro professor a outros alunos enquanto os colegas observam e recolhem dados e, por fim, refletem sobre essa aula. No entanto, 
Fujii (2016) refere que no Japão esta é uma situação bastante especial e tem vários inconvenientes. Para este autor, o objetivo do estudo de aula não é produzir uma "aula perfeita”, que não existe pois as aulas e as tarefas devem ser adaptadas às reais necessidades dos alunos. Aponta ainda que, essa reformulação influencia negativamente a natureza do planeamento e da própria discussão pós-aula que passa a centrar-se muito mais nas mudanças a fazer na aula do que na aprendizagem daqueles alunos e no que será necessário fazer para os levar a aprender o que não aprenderam com aquela tarefa.

Em Portugal incluímos também uma fase de seguimento depois da aula de observação. Contudo, as características desta fase de seguimento são muito diferentes da reformulação da aula acima descrita. Nas sessões de seguimento os professores planificam em conjunto mais uma ou duas aulas de modo a consolidarem e aplicarem os conhecimentos desenvolvidos durante o estudo de aula. Cada professor leciona a aula preparada em grupo e depois apresenta e discute com os colegas, na sessão seguinte, momentos e situações que considera pertinentes (PONTE; QUARESMA; MATA-PEREIRA; BAPTISTA, 2016).

Existem aspetos que influenciam fortemente os estudos de aula que são parte integrante do dia-a-dia e da cultura dos professores japoneses e que por vezes não são bem interpretados fora do Japão (FUJII, 2016). Nomeadamente, Lewis (2002) e Fujii (2016) referem algumas incompreensões. Em algumas situações confunde-se estudo de aula com planificação da aula, ignorando que a planificação da aula de investigação é apenas uma parte do estudo de aula. Outras vezes considera-se que no estudo de aula tem de haver a criação de novas aulas de raiz - os professores japoneses raramente o fazem durante um estudo de aula. Em vez disso, os professores fazem um levantamento das abordagens que melhor podem satisfazer o seu objetivo e depois focam-se na sua adaptação e refinamento. O foco está no melhoramento e não na criação. Há quem julgue que “estudo de aula significa escrever um guião rígido” (Lewis, 2002, p. 84). Na verdade, as aulas de investigação japonesas são planeadas de forma muito cuidadosa e detalhada, incluindo as questões que o professor vai colocar, a previsão das resoluções e do pensamentos dos alunos e possíveis ações para ajudar os alunos na sua aprendizagem, mas isso não significa que esse planeamento tem de ser seguido de forma rígida. Segundo Lewis (2002) existem também situações onde o “estudo de aula significa escrever o plano de aula 'perfeito’ para ser disseminado” (p. 84) mas nota que não existem planos de aula perfeitos, uma vez que devem estar adaptados aos alunos que são sempre diferentes uns dos outros. Por fim, Lewis (2002) aponta ainda que há quem considere que “a aula de investigação é uma aula de demonstração” (p. 85), contudo, a autora refere que nos estudos de aula no Japão existe uma igualdade de status entre todos os participantes. Os papéis são rotativos, assim todos os participantes aprendem em conjunto. 
Recentemente, em particular, em publicações com relatos de experiências nos EUA (LEWIS, 2016; TAKAHASHI; MCDOUGAL, 2016) têm sido apresentados modelos mais detalhados e que podem ajudar a ultrapassar algumas das incompreensões apresentadas. Nomeadamente, o modelo apresentado por Takahashi e McDougal (2016) designado por Collaborative Lesson Research (CLR) assume uma certa intenção de explicação pormenorizada do modelo japonês tendo em vista a sua implementação com maior sucesso fora do seu país de origem, especialmente nos EUA. Deste modelo, destacamos a definição do tema de investigação, um tema geral ou específico sobre o ensino e aprendizagem definido para toda a escola no final do ano letivo e que está na base de todo o trabalho desenvolvido na escola no ano letivo seguinte, incluindo os estudos de aula, que devem procurar dar resposta a questões levantadas com base neste tema. Apesar de também ser apresentado por outros autores, como Fujii (2014, 2016) apenas no CLR surge explicitamente no modelo como ponto de partida dos estudos de aula. Um segundo aspeto a salientar neste modelo é o destaque dado à fase de estudo dos documentos curriculares e de materiais de ensino que surge separadamente do planeamento, eventualmente, numa tentativa de salientar que no estudo de aula o planeamento da aula de investigação deve ser bem fundamentado. Para terminar há, ainda a salientar a fase de reflexão apresentada no CLR e por Fujii (2014, 2016), depois da discussão pós-aula os professores compilam todos os materiais produzidos para o estudo de aula como as tarefas e a planificação da aula e escrevem as suas reflexões sobre o trabalho desenvolvido no estudo de aula e sobre as aprendizagens realizadas, produzindo um documento que é depois divulgado numa publicação da escola. O estudo de aula coloca os professores no centro do seu processo de desenvolvimento profissional, tendo em conta os seus interesses e a vontade de compreender melhor a aprendizagem dos alunos com base nas suas próprias experiências.

\section{Abordagem exploratória versus "structured problem solving”}

O ensino e a aprendizagem da Matemática requerem que os professores aprofundem o seu conhecimento sobre os alunos, o conteúdo, o currículo e a didática, enquanto integram novas ideias para tornar a sua prática conceptualmente mais forte e mais centrada nos alunos (NCTM, 2007). Os professores usam esse conhecimento para tomar decisões sobre as experiências de aprendizagem a propor aos seus alunos, facilitando a construção de conexões entre as ideias dos alunos e os conceitos matemáticos. O estudo de aula permite cultivar uma nova atitude em relação ao ensino, nomeadamente como caminho que não é unidirecional e transmissivo, mas envolve uma integração bidirecional das ideias dos alunos e da exploração de conteúdos significativamente facilitadas pelos professores, um esforço que pode ser extremamente desafiante. No estudo de aula, a ênfase na 
aprendizagem do aluno permite que os professores tenham presente que é importante compreenderem as ideias dos alunos e permite-lhes trazer novas perspetivas para a sua sala de aula (MURATA, 2011).

No Japão o estudo de aula é um meio de motivar e encorajar os professores a usarem uma abordagem de sala de aula aberta, que denominam por structured problem solving (TAKAHASHI, 2014; FUJII, 2016; NI SHUILLEABHAIN; SEERY, 2017). Dessa abordagem fazem parte, tipicamente, a aula dividida em quatro fases principais e tarefas com características desafiantes e abertas. Assim, a aula é composta por: 1) hatsumon, apresentação pelo professor do problema ou questão para o dia; significa ajudar os alunos a compreenderem o contexto da tarefa de modo a envolvê-los e motivá-los mas exclui qualquer observação sobre o modo de resolução (5-10 min.); 2) kikan-shido, o trabalho dos alunos na resolução da tarefa mas também o trabalho de monitorização do professor que vai acompanhando o trabalho dos alunos tanto, para resolver eventuais dúvidas que estes possam ter, como para recolher informação para organizar a discussão (10-20 min.); 3) neriage, comparação e discussão das resoluções dos alunos, pressupõe que estes tenham chegado a diferentes métodos e resoluções; o foco está na discussão da fundamentação e na comparação das diferentes resoluções através da orquestração do professor e uma participação ativa dos alunos (1020 min.); 4) matome, síntese da aula pelo professor, com a revisão cuidadosa da discussão, de modo a orientar os alunos a desenvolver elevados níveis de sofisticação matemática (FUJII, 2016; SHIMIZU, 1999; TAKAHASHI, 2008).

Nesta abordagem são muito valorizadas as tarefas. Para potenciarem a estrutura da aula acima apresentada devem ser compreensíveis para que possam envolver ativa e positivamente os alunos na sua resolução. Além disso, devem ser acessíveis para, pelo menos, alguns alunos. Ao mesmo tempo têm de ser minimamente desafiantes, ou seja, não devem poder ser resolvidas instantaneamente apenas com os conhecimentos que os alunos já têm. Por fim, devem ainda permitir e potenciar o uso de diferentes estratégias de resolução para enriquecer a fase de discussão coletiva (FUJII, 2016).

Em Portugal, como base dos estudos de aula, tem vindo a ser seguida a abordagem curricular que denominamos por "exploratória" (PONTE, 2005). Esta perspetiva tem muitas semelhanças com "structured problem solving” japonês, mas está mais adequada à nossa realidade e contexto, dando continuidade ao trabalho desenvolvido nos últimos anos, nomeadamente nos programas de formação contínua. Nesta abordagem, os alunos trabalham em tarefas (não necessariamente problemas) em que têm que construir as suas próprias estratégias de resolução, usando com flexibilidade diferentes representações matemáticas. Para isso, o professor propõe aos alunos tarefas que os levem a desenvolver conceitos, representações e procedimentos matemáticos. 
A abordagem exploratória tem dois suportes principais, a escolha de tarefas apropriadas e o estabelecimento de um ambiente de comunicação na sala de aula capaz de favorecer a participação e reflexão por parte dos alunos, com relevo para os momentos de discussão coletiva, que valorizam a negociação de significados e argumentação. Esta abordagem enfatiza a construção de conceitos, a modelação de situações e também a utilização de definições e propriedades de objetos matemáticos para chegar a conclusões. Outro aspeto muito importante e que não é tão saliente no Japão é a sua atenção ao raciocínio matemático dos alunos, especialmente no que respeita à realização de conjeturas e generalizações (raciocínio indutivo e abdutivo) e justificações utilizando propriedades matemáticas, definições ou representações (raciocínio dedutivo) (MATA-PEREIRA; PONTE, 2013). Esta atenção materializa-se na condução das sessões do estudo de aula, através da análise de tarefas e de exemplos de trabalho escrito dos alunos e de diálogos na sala de aula. A estrutura da aula tende a seguir três fases - introdução da tarefa, trabalho autónomo dos alunos e discussão e síntese que, muitas vezes, surgem de modo interligado.

\section{Metodologia de investigação}

Esta investigação, de natureza qualitativa e interpretativa (ERICKSON, 1986), tem por base um estudo de aula realizado no ano letivo de 2013-2014 num agrupamento de escolas de Lisboa. Para concretizar a formação dos professores solicitada pela escola propusemos a realização de diversos estudos de aula, sendo um deles com três professores do $1 .^{\circ}$ ciclo do agrupamento. A equipa do Instituto de Educação da Universidade de Lisboa (IE) que conduziu este trabalho era formada por três membros, tendo Marisa dinamizado as sessões de trabalho, João Pedro coordenado a formação e participado em algumas sessões e Mónica participado no papel de observadora, coadjuvada por uma bolseira. Na aula de investigação participam os três professores, os membros da nossa equipa e ainda a subdiretora da escola.

O estudo de aula teve nove sessões de trabalho, a que se seguiram três sessões de seguimento. A sessão 1 teve por objetivo apresentar o estudo de aula a todos os professores participantes, as sessões 2 a 7 pretenderam aprofundar o conhecimento sobre o tópico escolhido e preparar uma aula sobre esse tópico, sendo que a sessão 6 foi integralmente dedicada à conceção da tarefa a usar na aula de investigação, a sessão 8 consistiu na observação de uma aula, e a sessão 9 foi dedicada a refletir sobre a aula observada e sobre o trabalho realizado até aí. Nas sessões 10 a 12 pedimos às professoras que planificassem, realizassem e refletissem sobre duas aulas de acordo com o trabalho desenvolvido durante o estudo de aula. 
Os dados foram recolhidos por observação participante com elaboração de um diário de bordo (por um membro da equipa), gravação áudio das sessões ( $\mathrm{S} x$ ) e vídeo da aula de investigação, sendo sempre feitas as respetivas transcrições, e ainda entrevistas individuais (E) às professoras participantes e um relatório final (RF) onde as professoras fizeram a sua análise do estudo de aula. Os dados foram analisados de forma indutiva, procurando identificar no discurso das professoras temas ilustrativos da sua perceção sobre o estudo de aula em que participaram, mais concretamente sobre a dinâmica do processo e sobre a abordagem exploratória (tarefas, comunicação e raciocínio).

\section{O estudo de aula com professores do $1 .^{\circ}$ ciclo}

O estudo de aula começou por envolver sete professores de duas escolas do $1 .^{\circ}$ ciclo do agrupamento, cinco professoras da escola onde se iam realizar as sessões de trabalho e dois professores de outra escola do agrupamento. Por diferentes motivos, quer da vida pessoal e profissional, quer por não estarem a lecionar o $3 .^{\circ}$ ano, quatro destes professores rapidamente desistiram da formação e o grupo ficou reduzido a três professoras - Irina, Manuela e Antónia. As três professoras eram já efetivas e experientes, tendo cerca de 10 a 15 anos de serviço.

O estudo de aula incidiu sobre um tópico do $3 .^{\circ}$ ano, escolha que resultou do facto de estarem a ser introduzidas novas orientações curriculares. Assim, um aspeto marcante deste estudo de aula foi o tópico escolhido - adição e subtração de números racionais por justaposição retilínea de segmentos de reta. Segundo as professores, este era um dos tópicos que tinha sofrido alterações mais profundas nas novas orientações curriculares e o que podia causar mais dificuldades a professoras e alunos. Um segundo aspeto a destacar do estudo de aula foi a realização do diagnóstico dos conhecimentos dos alunos. Para Antónia foi importante saber “o que é que tinha ficado" do trabalho desenvolvido no ano anterior e para Irina foi uma surpresa porque "até percebemos que eles [os alunos] sabiam mais do que aquilo que estávamos à espera no início”.

Outro aspeto a destacar e que se reveste de um certo cariz inovador foi a elaboração da tarefa para a aula de investigação. Por um lado, Irina sente-se muito à vontade com os conteúdos matemáticos, gosta e sente-se confiante para criar tarefas. Por outro lado, como estavam a ser introduzidas mudanças muito fortes no novo programa, esta professora sentia que ainda não existia grande diversidade nos materiais produzidos para o $1 .^{\circ}$ ciclo e não se sentiu satisfeita com o que encontrou: “ainda não são muitas as fontes onde recorrer para tirar ideias de tarefas a explorar na sala de aula” (RF). Uma vez que iria lecionar a aula de investigação, pediu-nos para dedicarmos uma sessão à elaboração e discussão da tarefa em grupo. Assim, a sessão 6 foi integralmente dedicada à elaboração da tarefa. Irina liderou em grande parte este trabalho e a equipa do IE foi 
apoiando e guiando a discussão e desafiando as professoras a refletirem sobre os diferentes aspetos da tarefa e da aula. Antónia e Manuela foram bastante participativas a discutir as ideias apresentadas pela colega, mas não se sentiam suficientemente confiantes para tomar iniciativa e fazer sugestões muito elaboradas.

\section{Dinâmica do estudo de aula}

Na última sessão fez-se um balanço global de todo o processo, no estilo de uma entrevista em grupo focal. Procurámos fazer um levantamento dos acontecimentos das várias sessões de trabalho e questionar as professoras sobre esses acontecimentos. Assim, começámos por recordar a primeira sessão em que foi apresentado o modelo do estudo de aula aos professores, onde se apresentaram vários exemplos do Japão e dos EUA. Nessa sessão os professores, qua ainda não conheciam este modelo de formação, ficaram muito curiosos e fizeram várias questões sobre o seu funcionamento. Irina tentou fazer um resumo daquilo que sentiu e das questões levantadas pelos colegas. Referindose ao elevado número de observadores que viu nos vídeos de apresentação do modelo, recordou que ficou atrapalhada porque "era muita gente quando vocês mostraram aquilo, fez-me confusão", comentando depois com as colegas “Bem, na minha sala, eu nem quero pensar”. Manuela e Antónia referiram também a sua estranheza e desconforto em relação ao elevado número de observadores na aula de investigação. O segundo aspeto que causou estranheza no grupo foi o facto de ser centrado num único tópico. Irina referiu que "Até pensei: Bom, como é que vamos ter tema para tantas sessões, como é vamos estar tanto tempo a falar do mesmo?” (S12) Esta estranheza inicial sobre o formato focado num único tópico acabou por se dissipar ao longo das sessões e Manuela refere que “Mas de facto só depois de termos passado por este processo todo é que verificámos que de facto faz sentido estar à volta de um tema” (S12). Contudo, no final, as três participantes continuam a afirmar que preferiam um estudo de aula numa versão “mais generalista” porque gostavam de abordar diversos tópicos.

A aula de investigação foi o elemento central deste estudo de aula. Primeiro gerou tensão na decisão de quem a iria lecionar. Irina recorda a conversa com as colegas no final da sessão 1 , “Foi engraçado perceber que ninguém queria dar aquela aula: Ai, não! Mas porque é que tenho de ser eu? Ai, não! Isso logo se vê...” Na entrevista focal, percebeu-se também que as cinco primeiras sessões foram pautadas por uma tensão no grupo por ainda não estar definido quem iria lecionar a aula de investigação: 
Eu acho que a tensão começou a dissipar quando eu disse "eu não me importo de ser eu”. Aí eu acho que a coisa acalmou um bocado. Acalmou? Não. Aliviou. Eu sabia que a coisa ia-me calhar a mim. (Irina, S12)

Como Irina é professora de Matemática do $2 .^{\circ}$ ciclo e mostrava muita confiança e conhecimento, as colegas começaram desde a primeira sessão a "sugerir" que devia ser ela a lecionar a aula de investigação. Por seu lado, Irina estava convicta que, precisamente, por estar mais à vontade com a Matemática é que devia ser outra colega a lecionar a aula porque isso podia proporcionar-lhe uma aprendizagem mais rica do que a si própria.

Após a tensão inicial da escolha de quem iria lecionar a aula, a sua aproximação despertou um grande interesse e motivação nas professoras. A aula acabou por constituir uma grande satisfação tanto para a professora que a lecionou, como para as colegas:

Irina: Comecei a ver aquilo e pensei: "Mas tu sabes isto! Estás agora a decorar! Mas o que é isto?”... E primeiro que adormecesse... Os primeiros cinco minutos [da aula] estava nervosa, a partir daí... Aliás, vocês passaram como pessoas que eu até já estava a conversar, e achei isso interessante. Vocês deixaram de ser pessoas à parte para serem pessoas que estavam ali comigo, a partir daí, pronto, foi... Mas o início foi complicado.

Marisa: E gostou?

Irina: Gostei. (S12)

Irina revelou que se sentiu muito nervosa com a preparação da aula, com a responsabilidade da lecionação, mas que, passado esse nervosismo, gostou da experiência. Refere ainda que só esteve nervosa nos primeiros minutos da aula e depois conseguiu começar a olhar para o grupo como o seu grupo de trabalho e não como "avaliadores" e que a partir desse momento conseguiu acalmar e até interagir com os observadores.

Por seu lado, Antónia gostou de observar a aula, considera que esta “correu muito bem” e gostou também da relação com os alunos. Para Manuela aula observada constituiu uma importante experiência:

Manuela: Aquilo que aconteceu no nosso grupo pode não representar outros. Eu acho que para mim foi uma maisvalia ter assistido à aula da Irina, sem dúvida nenhuma!

$\begin{aligned} \text { João } & \text { Porquê? }\end{aligned}$

Manuela: Porque acho que a segurança e a forma como ela encara a Matemática... Eu estava a ouvi-la... E acho que tenho sempre a aprender com a Irina.

Irina: Temos sempre muito a aprender uns com os outros.

Manuela: (...) Aprendi muito mais do que se calhar se tivesse sido 
eu a aplicar a aula. (S12)

Manuela manifestou uma grande admiração pelo à vontade e segurança com que Irina lecionou a aula.

Quando questionadas sobre o papel das três sessões de seguimento, Manuela e Antónia consideraram que foi importante a existência deste momento de formação:

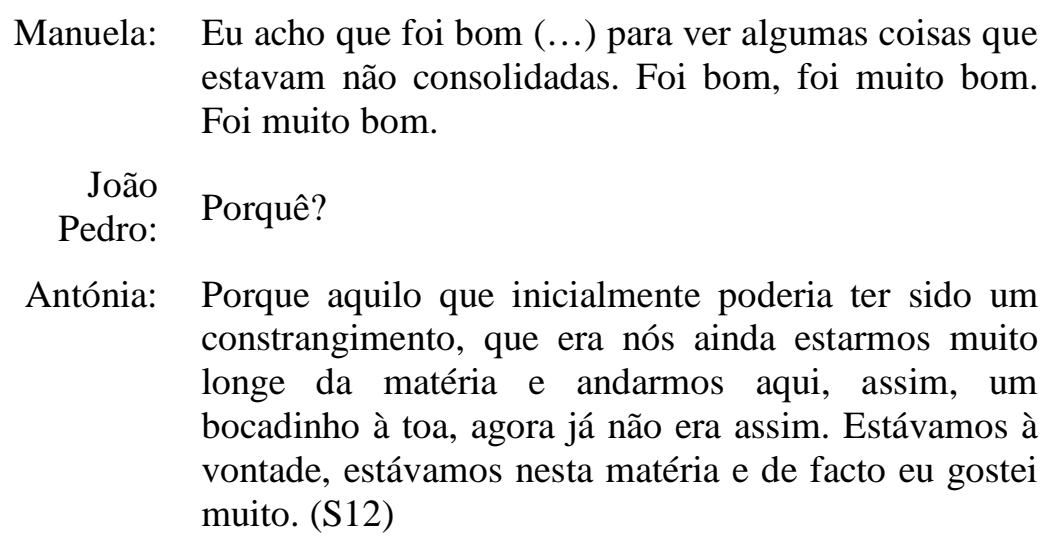

Manuela referiu que foi um bom momento para consolidar alguns aspetos sobre o ensino do tema e Antónia destacou aqui uma alteração em relação às primeiras sessões, pois agora já estavam envolvidas no tema, estiveram a preparar uma aula para o conteúdo específico que estavam a trabalhar com os alunos. Esta última fase também se pautou por um maior companheirismo entre as professoras. Na primeira sessão do seguimento (sessão 10), as professoras planearam uma nova aula de acordo com o trabalho desenvolvido durante o estudo de aula e, Manuela e Antónia propuseram escolher o tópico que estavam a lecionar para “aliviar” um pouco Irina, reconhecendo que tinha sido muito sobrecarregada durante a fase anterior do estudo de aula.

\section{Abordagem exploratória}

Na organização da aula de investigação, as professoras procuram por em prática a estrutura de aula própria da abordagem exploratória. Sobre a discussão em torno da natureza das tarefas, as três professoras foram unânimes em salientar a importância de variar o tipo de tarefas a apresentar aos seus alunos, Irina refere que este trabalho a "fez refletir um bocadinho no tipo de coisas que apresento aos alunos e a importância de uma ficha de trabalho, por exemplo, não ser só exercícios. Nós (...) quando estamos a fazer uma ficha às vezes não temos essa visão, mas... Ai! são poucos, mais um, mais dois e não estamos a ver a natureza do exercício” (S12). Irina identificou a análise de tarefas, a comunicação e a organização dos alunos como os elementos da abordagem exploratória mais pertinentes e que que parecem ter influenciado a maneira como encara a sua prática: 
O facto desta oficina de formação ter estado tão focada numa determinada aula com um conteúdo específico fez com que a atenção dada às tarefas fosse maior e houvesse um esmiuçar de cada uma delas com um sentido muito crítico. Isto levoume a estar mais atenta a pormenores como: linguagem utilizada nos enunciados (se é suficientemente clara e acessível); tipo de tarefa; como deve ser trabalhada (individualmente ou em grupo); tempo dado; tipo de ajudas que podem/devem ser dadas; questões que podem ser levantadas durante a apresentação dos resultados (...), provocando uma alteração na minha postura na sala de aula. (RF)

Por seu lado, Manuela destaca aprendizagens sobre a comunicação na sala de aula, em particular a importância de ouvir mais os alunos: "vou estar mais atenta àquelas cabeças e àquilo que sair da boca deles (...) Irei pegar em questões fundamentais que saiam deles” (E). Esta professora salienta também a necessidade de promover o desenvolvimento da comunicação matemática dos alunos e de dar-lhes um papel mais ativo: "interiorizei que o aluno deve ser estimulado a explicar, bem como a argumentar e comprovar determinada estratégia ou raciocínio” (RF). A forma veemente como Manuela destaca a comunicação e o papel ativo dos alunos na sala de aula parece estar relacionada com resultados positivos e surpreendentes que teve no trabalho que desenvolveu com os seus alunos usando esta metodologia:

Ao aplicar as várias tarefas que me foram propostas nas sessões fui sempre surpreendida por um conjunto de alunos, no que diz respeito a estratégias por eles pensadas e aplicadas (...) Fui, igualmente, surpreendida por alunos que no seu trabalho diário revelam dificuldades, mas que, perante a proposta do trabalho, não cruzaram os braços e, juntamente com o seu parceiro de grupo, conseguiram realizar um trabalho positivo. Foi notório que eles próprios se sentiram surpreendidos com o seu desempenho e consequente prestação. A sua felicidade e orgulho estavam claramente estampados nos seus rostos. (RF)

As professoras valorizaram, também, o trabalho de cunho exploratório desenvolvido nas sessões do estudo de aula em torno das tarefas, salientando a importância de resolverem tarefas matemáticas. Para Antónia a resolução das tarefas foi uma oportunidade para ela própria aprofundar o seu conhecimento matemático: “é a resolver essas tarefas que nós também apendemos e sentimos as dificuldades que depois poderemos ter na sala de aula” (S12). Para Irina, a reflexão sobre as possíveis dificuldades dos alunos foi uma boa oportunidade para desenvolver conhecimento didático "Eu acho que dá-nos logo uma preparação para pensarmos como é que nós vamos ultrapassar e ajudá-los a ultrapassar” (S12). Por fim, Antónia destacou que lhe agradou em especial a componente prática deste momento do estudo de aula: “é sempre uma componente prática. Eu acho que isso é bom” (S12). Esta professora destaca um aspeto da própria dinâmica do estudo de aula, o uso da abordagem exploratória com momentos mais práticos também no trabalho com as professoras e não apenas como recomendação para a sala de aula, dando-lhes oportunidade de experienciar também o trabalho nessa abordagem. 


\section{Conclusão}

Em termos de orientação curricular, o traço principal deste estudo de aula com professores do $3 .^{\circ}$ ano é a ênfase na abordagem exploratória. Em termos de organização, destaca-se a valorização do trabalho em torno das tarefas, da comunicação, a aula de investigação e as sessões de seguimento. As professoras participantes neste estudo valorizam a abordagem curricular seguida, reconhecendo a importância de diversificar as tarefas, de promover o desenvolvimento da comunicação dos alunos, de dar aos alunos um papel mais ativo na sua aprendizagem bem como as potencialidades de um trabalho de natureza muito prática que tiveram oportunidade de experimentar também durante as sessões. Valorizam, também, a dinâmica do processo formativo, destacando em especial a aula de investigação como tendo constituído uma experiência de aprendizagem muito rica. Importa destacar que, apesar de causadora de momentos difíceis na constituição e vivência deste grupo de professoras, a aula de investigação acabou por ter um papel agregador e de união do grupo. Por um lado, Antónia e Manuela reconhecem as aprendizagens desenvolvidas na observação da aula e, por outro lado, Irina refere que durante a aula de investigação passou a ver os membros da equipa do IE também como "colegas" encurtando as distâncias e as diferenças nos papéis desempenhados por cada um dos participantes.

De modo semelhante ao que referem Ni Shuilleabhain e Seery (2017) e Fujii (2016), as professoras aproveitaram esta oportunidade de trabalho colaborativo para se prepararem para a lecionação de novos assuntos e práticas. Por um lado, o grupo aproveitou de modo interessante e produtivo para estudar um tópico que estava a ser introduzido naquele momento no currículo e que sentiam que causava dificuldades tanto aos seus alunos como a elas próprias. Por outro lado, em particular Irina, aproveitou a oportunidade de ter o apoio da equipa de formadores para produzir tarefas que the pareciam mais adequadas ao desenvolvimento da compreensão dos alunos do que as que conhecia nos materiais de ensino disponíveis para o 1. ${ }^{\circ}$ ciclo. Assim, apesar de Lewis (2002) desvalorizar a necessidade que alguns professores participantes em estudos de aula sentem em elaborar tarefas e aulas de raiz, parece-nos que esta vontade de Irina se prende sobretudo com a confiança que tem com o conteúdo matemático e com a sua insatisfação em relação aos materiais de ensino que conhece.

As professoras valorizam todo o trabalho desenvolvido no estudo de aula em torno do conteúdo específico e dos aspetos curriculares e didáticos de caráter transversal abordados sobre natureza das tarefas, a comunicação e o raciocínio. Contudo, no final do estudo de aula, as 
professoras continuam a referir que preferiam um modelo de trabalho que valorizasse mais os aspetos diretamente relacionados com o conteúdo matemático específico.

Na nossa abordagem aos estudos de aula, estes constituem uma pequena investigação coletiva do grupo de participantes, realizada na sua própria prática (PONTE, 2002). Começamos com a formulação de uma questão de partida, efetuamos um trabalho sistemático para preparar uma experiência (a aula de investigação), recolhemos e analisamos dados sobre essa aula e tentamos aplicar o conhecimento resultante deste processo a outras situações. Numa perspetiva que se aproxima do CLR descrito por Takahashi e McDougal (2016) procuramos que os estudos de aula que desenvolvemos partam das reais necessidades dos alunos. Para isso realizamos um diagnóstico dos conhecimentos dos alunos, analisamos os resultados e partimos daí para a planificação da aula de investigação. Dedicamos cerca de cinco sessões de trabalho à análise dos documentos curriculares e de documentos de ensino sobre o conteúdo específico e sobre a abordagem curricular subjacente, delimitando bem esta fase da fase seguinte de planeamento específico da aula. Por fim, consideramos que as sessões de seguimento, embora tivessem surgido de modo circunstancial, revelaram constituir um momento muito importante de trabalho, levando os professores participantes a assumir maior iniciativa e ajudando-os a pôr em prática e aprofundar a reflexão sobre as questões trabalhadas durante a fase inicial do estudo de aula. Procuramos fazer este trabalho com os professores também de um modo exploratório e num ambiente colaborativo, ou seja, em vez de dizermos como os "professores devem agir”, procuramos criar situações em que sejam eles, através do seu trabalho coletivo, a descobrir como atuar e o balanço feito pelas professoras participantes encoraja-nos a prosseguir esta linha de trabalho.

\section{Agradecimento}

Trabalho financiado por fundos nacionais através da FCT-Fundação para a Ciência e Tecnologia por meio de uma bolsa atribuída a Marisa Quaresma (SFRH/BD/97702/2013).

\section{Referências}

DOIG, B.; GROVES, S. Japanese lesson study: Teacher professional development through communities of inquiry. Mathematics Teacher Education and Development, Australia, v. 13, n. 1, p.77-93, 2012.

ERICKSON, F. Qualitative methods in research on teaching. In: WITTROCK, M. C. (Org.), Handbook of research on teaching. New York, NY: MacMillan, 1986. p. 119-161.

FERNANDEZ, C.; YOSHIDA, M. Lesson study: A Japanese approach to improving mathematics teaching and learning. Mahwah, NJ: Lawrence Erlbaum, 2004. 
FUJII, T. Implementing Japanese Lesson Study in foreign countries: Misconceptions revealed. Mathematics Teacher Education and Development, Australia, v. 16, n. 1, p.65-83, 2014.

FUJII, T. Designing and adapting tasks in lesson planning: a critical process of Lesson Study. ZDM Mathematics Education, Netherlands, v. 48, n.4, p.411-423, 2016.

LEWIS, C. Lesson study: A handbook of teacher-led instructional improvement. Philadelphia: Research for Better Schools, 2002.

LEWIS, C. How does lesson study improve mathematics instruction? ZDM Mathematics

Education, Netherlands, v. 48, n.4, p.571-580, 2016.

LEWIS, C.; PERRY, R. Lesson study to scale up research-based knowledge: A randomized, controlled trial of fractions learning. Journal for Research in Mathematics Education, Reston, VA, v. 48, n.3, p. 261-299, 2017.

MATA-PEREIRA, J.; PONTE, J. P. Desenvolvendo o raciocínio matemático: Generalização e justificação no estudo das inequações. Boletim GEPEM, Seropédica, RJ, v. 62, p. 17-31, 2013.

MURATA, A. Introduction: Conceptual overview of lesson study. In: HART, L. C.; ALSTON, A.S.; MURATA, A. (Orgs.), Lesson study research and practice in mathematics education. New York, NY: Springer, 2011. p.1-12.

NCTM. Princípios e normas para a Matemática escolar. Lisboa: APM, 2007.

NI SHUILLEABHAIN, Aoibhinn; SEERY, Aidan. Enacting curriculum reform through lesson study: a case study of mathematics teacher learning. Professional Development in Education. P.115, 2017 (DOI: 10.1080/19415257.2017.1280521)

(<http://www.tandfonline.com/eprint/MFYDSIdPgc6SSBTzNnQV/full>, Acesso em: 18/04/2017)

PONTE, J. P. Investigar a nossa própria prática. In GTI (Org.), Reflectir e investigar sobre a prática profissional. Lisboa: APM, 2002. p.5-28.

PONTE, J. P. Gestão curricular em Matemática. In GTI (Org.), O professor e o desenvolvimento curricular. Lisboa: APM, 2005. p.11-34.

PONTE, J. P.; QUARESMA, M.; MATA-PEREIRA, J.; BAPTISTA, M. O estudo de aula como processo de desenvolvimento profissional de professores de matemática. Bolema, Rio Claro, v. 30, n. 56, p. 868-891, 2016.

SHIMIZU, Y. Working at the intersection of research and practice: A perspective on the study and improvement of mathematics lessons. In: STEINLE, V.; BALL, L.; BARDINI, C. (Orgs.),

Mathematics education: Yesterday, today and tomorrow. (Proceedings of the $36^{\text {th }}$ annual conference of the Mathematics Education Research Group of Australia). Melbourne, VIC:

MERGA, 2013. p. 2-12. Notas. Disponível em:

<https://www.merga.net.au/documents/Shimizu_MERGA36-2013.pdf>. Acesso em: 18/04/2017.

SHIMIZU, Y. Aspects of mathematical teacher education in Japan: Focusing on the teachers' roles. Journal of Mathematics Teacher Education. Netherlands, v. 2, p. 107-116, 1999.

SHIMIZU, Y. Lesson study in Mathematics education. In: LERMAN, S. (Ed.), Encyclopedia of mathematics education Dordrecht: Springer, 2014. p.358-360.

STIGLER, J.; HIEBERT, J. The teaching gap. New York, NY: Free Press, 1999.

TAKAHASHI, A. Beyond show and tell: Neriage for teaching though problem solving - Ideias from Japanese problem-solving approaches for teaching mathematics. In: ICME, n. 11, 2008, Monterey, Mexico (Paper presented at topic Group 19: Research and development in problem 
solving mathematics education). Notas. Disponível em: <http://tsg.icme11.org/document/get/827> . Acesso em: 18/04/2017.

TAKAHASHI, A. Supporting the effective implementation of a new mathematics curriculum: a case study of schoolbased lesson study at a Japanese public elementary school. In: LI, Y.;

LAPPAN, G. (Ogs.). Mathematics curriculum in school education. Dordrecht: Springer, 2014. p. $417-441$.

TAKAHASHI, A.; MCDOUGAL, T. Collaborative lesson research: Maximizing the impact of lesson study. ZDM Mathematics Education, Netherlands, v. 48, n. 4, p. 513-526, 2016.

WAKE, G.; SWAN, M.; FOSTER, C. Professional learning through the collaborative design of problem-solving lessons. Journal of Mathematics Teacher Education. Netherlands, v. 19, n. 2-3, p. 243-260, 2016. 